University of Nebraska - Lincoln

DigitalCommons@University of Nebraska - Lincoln

\title{
International shipping of fumonisins from maize extracts on $\mathrm{C}_{18}$ sorbent
}

\author{
R. T. Riley
}

USDA-ARS, ron.riley@ars.usda.gov

O. A. Torres

Instituto de Nutricion de Centro America y Panama

E. Palencia

Instituto de Nutricion de Centro America y Panama

Follow this and additional works at: https://digitalcommons.unl.edu/usdaarsfacpub

Part of the Agricultural Science Commons

Riley, R. T.; Torres, O. A.; and Palencia, E., "International shipping of fumonisins from maize extracts on $\mathrm{C}_{18}$ sorbent" (2006). Publications from USDA-ARS / UNL Faculty. 583.

https://digitalcommons.unl.edu/usdaarsfacpub/583

This Article is brought to you for free and open access by the U.S. Department of Agriculture: Agricultural Research Service, Lincoln, Nebraska at DigitalCommons@University of Nebraska - Lincoln. It has been accepted for inclusion in Publications from USDA-ARS / UNL Faculty by an authorized administrator of DigitalCommons@University of Nebraska - Lincoln. 


\title{
International shipping of fumonisins from maize extracts on $\mathrm{C}_{18}$ sorbent
}

\author{
R. T. RILEY ${ }^{1}$, O. A. TORRES ${ }^{2}$, \& E. PALENCIA ${ }^{2}$ \\ ${ }^{1}$ Toxicology and Mycotoxin Research Unit, R. B. Russell Agricultural Research Center USDA-ARS, PO Box 5677, \\ Athens, GA 30604, USA and ${ }^{2}$ Instituto de Nutricion de Centro America y Panama, Calzada Roosevelt, \\ Zone 11, Apartado Postal 1188, 09001 Guatemala, Central America
}

(Received 27 Fanuary 2006; revised 14 March 2006; accepted 15 March 2006)

\begin{abstract}
Fumonisins are mycotoxins found in maize. In developing countries, the resources required for analysis are often lacking, and the shipping of maize between countries can be difficult since the importation of plant materials requires permits/ inspection to prevent the entry of pests that frequently infest maize. A simple, safe and legal method for shipping maize extracts to the USA was needed to conduct a survey of fumonisins in Central America. The objective was to develop a method for isolating and shipping maize extracts for fumonisin analysis so as to facilitate a survey of fumonisin exposure. The results indicate that fumonisins in acetonitrile:water extracts of maize can be isolated on $\mathrm{C}_{18}$ cartridges, held for at least 3 days at $22^{\circ} \mathrm{C}$ and then an additional 4 days at $4{ }^{\circ} \mathrm{C}$ before elution and analysis with no losses. This method allows the importation and analysis of maize samples from foreign locations without complications from international safety concerns.
\end{abstract}

Keywords: Fumonisin $B_{1}$, Fusarium verticillioides, maize, liquid chromatography electrospray ionization mass spectrometry (LC/MS)

\section{Introduction}

Fumonisins are mycotoxins produced by the fungus Fusarium verticillioides (formerly $F$ moniliforme). Fumonisin $\mathrm{B}_{1}\left(\mathrm{FB}_{1}\right)$ is the most abundant of the naturally occurring fumonisin congeners (Rheeder et al. 2002).

Fumonisins are a concern for maize producers, processors, consumers, and regulators. The occurrence and contamination of maize is worldwide and fumonisins are known to cause farm animal diseases including equine leucoencephalomalacia and porcine pulmonary oedema (Bolger et al. 2001, and references therein), are possible human carcinogens (International Agency for Research on Cancer (IARC) 2002) and are suspected risk factors for human neural tube defects (Marasas et al. 2004). There are currently several methods used to measure fumonisins in various matrices (Bolger et al. 2001, and references therein). One of the most common methods for quantitative analysis in maize is solvent extraction, solid-phase clean-up and ortho-phthalaldehyde plus 2-mercaptoethanol derivatization followed by high-performance liquid chromatography (HPLC) separation and quantification of the fluorescent $\mathrm{FB}_{1}$ derivative (Shephard 1998, and references therein). Several liquid chromatography electrospray ionization-mass spectrometry (LC/MS) methods have also been developed that are very sensitive and do not require derivatization (Joseph 1996; Musser 1996; Plattner et al. 1996; Plattner 1999).

Exposure to fumonisins occurs through the consumption of maize and maize products. People living in areas of the world where maize consumption is high are at the greatest risk of consuming amounts of fumonisins that exceed the provisional maximal tolerable daily intake proposed by the World Health Organization (WHO)/Food and Agriculture Organization (FAO) Joint Expert Committee on Food Additives (JECFA) (Bolger et al. 2001). These include southern Africa, parts of China, Mexico, 
parts of South America and most of Central America (Marasas et al. 2004). Therefore, the greatest need for accurate exposure assessment, upon which risk management decisions are based, is in countries where the resources for accurate analysis and confirmation are often limited.

The present study was conducted to determine fumonisin stability when isolated from maize extracts on $\mathrm{C}_{18}$ solid-phase extraction cartridges. The specific objectives were (1) to develop and validate a method for extracting, isolating, and shipping maize extracts; and (2) to couple the method compatibly with a reproducible and sensitive analytical method.

\section{Materials and methods}

\section{Materials and test agents}

The analytical standards of $\mathrm{FB}_{1}$, fumonisin $\mathrm{B}_{2}\left(\mathrm{FB}_{2}\right)$ and fumonisin $\mathrm{B}_{3}\left(\mathrm{FB}_{3}\right)$ were a gift from Ronald Plattner (USDA-ARS, Peoria, IL, USA) and the purity $(>96 \%)$ was determined by the procedure of Plattner and Branham (1994). Working stock solutions at 50 and $5 \mu \mathrm{g} \mu \mathrm{l}^{-1}$ containing $\mathrm{FB}_{1}, \mathrm{FB}_{2}$ and $\mathrm{FB}_{3}$ were prepared in acetonitrile:water $(1: 1)$. Phytosphingosine (Pso) was obtained from Sigma Chemical Co. (\# D2795; St Louis, MO, USA). A $0.010 \mu \mathrm{g}^{-1}$ Pso standard prepared from Pso stock $\left(0.32 \mu \mathrm{g} \mu \mathrm{l}^{-1}\right.$ in ethanol) was used as an internal quality control check for instrument performance. $\mathrm{C}_{18}$ Sep-Pak ${ }^{\circledR}$ Cartridges were obtained from Waters (\# WAT051910; Milford MA, USA).

Dry shelled maize used to determine fumonisin extraction efficiency with $\mathrm{FB}_{1}, \mathrm{FB}_{2}$ and $\mathrm{FB}_{3}$ spiked samples and as a source of diluent in the stability studies (to be described below) was ground $(2 \mathrm{~mm}$ ) using a Romer Mill (Romer Labs, Union, MO, USA) and extracted and analysed as described below. Two lots of 'clean maize' (CM1 and CM2) and two lots of heavily contaminated maize (HCM1 and HCM2) were prepared. CM1 contained $0.138 \pm 0.013, \quad 0.040 \pm 0.001, \quad$ and $0.013 \pm 0.003 \mu \mathrm{g} \mathrm{g}^{-1}$ maize $(n=3)$ of $\mathrm{FB}_{1}, \mathrm{FB}_{2}$ and $\mathrm{FB}_{3}$, respectively; $\mathrm{CM} 2$ contained $0.0398 \pm 0.0066$, $0.0284 \pm 0.0036$ and $0.0105 \pm 0.0006 \mu \mathrm{gg}^{-1}$ maize $(n=5)$ of $\mathrm{FB}_{1}, \mathrm{FB}_{2}$ and $\mathrm{FB}_{3}$, respectively.

Dry maize heavily contaminated with Fusarium verticillioides and showing varying signs of maize-ear rot was obtained from North Carolina, USA, in 1999. The HCM was hand shelled and segregated so as to contain predominately intact kernels. HCM1 contained $46.8 \pm 3.2, \quad 13.5 \pm 0.1$, and $10.7 \pm 0.3 \mu \mathrm{g} \mathrm{g}^{-1}$ maize $(n=3)$ of $\mathrm{FB}_{1}, \mathrm{FB}_{2}$ and

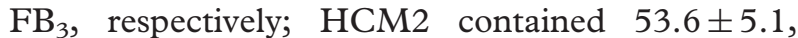
$17.0 \pm 0.9$, and $11.9 \pm 0.4 \mu \mathrm{g} \mathrm{g}^{-1}$ maize $(n=5)$ of $\mathrm{FB}_{1}, \mathrm{FB}_{2}$ and $\mathrm{FB}_{3}$, respectively. The $\mathrm{HCM}$ was used to obtain extracts to use for determining the stability of fumonisins isolated on $\mathrm{C}_{18}$ cartridges and for other analyses to determine the compatibility of the $\mathrm{C}_{18}$-cartridge eluates with electrospray ionization (ESI) ion-trap mass spectrometry (LC/MS) as described below.

\section{Liquid chromatography/mass spectrometry/mass spectrometry (LC-MS/MS) of fumonisins}

Fumonisins were chromatographically separated essentially as described by Plattner (1999), except that the column was equilibrated for $7 \mathrm{~min}$ at $0.2 \mathrm{ml} \mathrm{min}^{-1}$ with $30 \%$ solvent A $(97 \%$ acetonitrile : $2 \%$ water : $1 \%$ formic acid) and $70 \%$ solvent $\mathrm{B}$ ( $2 \%$ acetonitrile : $97 \%$ water : $1 \%$ formic acid) and then at injection a gradient began, where ' $\mathrm{A}$ ' was increased to $60 \%$ at $15 \mathrm{~min}$ and then $90 \%$ at $20 \mathrm{~min}$, and at $22 \mathrm{~min}$ the composition was returned to $30 \%$ ' $\mathrm{A}$ '. The MS detector was tuned in a manner similar to that described previously (Plattner 1999). However, three separate scan segments were used and $(m / z=722.3,706.3$ and 318.2) timed so as to isolate $\mathrm{FB}_{1}, \mathrm{FB}_{2}$ and $\mathrm{FB}_{3}$, and Pso. The collision energy was $32 \%$.

Quantification was accomplished using external standardization and instrument performance was monitored by spiking extracted samples with Pso. The correlation coefficient $\left(r^{2}\right)$ of the standard curve for each fumonisin was $>0.99$. The Pso working standard used as an internal quality control check for instrument performance among samples was added to each standard and sample vial so that the final Pso concentration was $0.1 \mathrm{ng} \mathrm{Pso} / \mu \mathrm{l}$ of sample. Pso is naturally present in maize kernels. However, after clean-up on $\mathrm{C}_{18}$ cartridges, the endogenous levels are much less than the amount of Pso spiked into each sample vial.

Fumonisin extraction procedure and isolation on $C_{18}$ cartridges

The maize extraction procedure and isolation on $\mathrm{C}_{18}$ cartridges was similar to that described by Rice et al. (1995). Briefly, dry shelled maize $(>1 \mathrm{~kg}$ ) was ground using a Romer Mill and then carefully mixed 5 -g samples were placed in flasks and $25 \mathrm{ml}$ of acetonitrile:water $(1: 1, \mathrm{v} / \mathrm{v})$ were added, mixed, and the $\mathrm{pH}$ adjusted to 4.5 with $1 \mathrm{~N} \mathrm{HCl}$. The mixture was placed on a reciprocating shaker at high speed and extracted for $16 \mathrm{~h}$ at $21-23^{\circ} \mathrm{C}$. After $16 \mathrm{~h}$ the samples were filtered and then $2 \mathrm{ml}$ of the extract were diluted with $6 \mathrm{ml}$ of water. Up to 20 cartridges were prepared as described by Rice et al. (1995) at one time before loading samples. It is critical not to allow the cartridges to run dry of solvent between rinses since air drying of the $\mathrm{C}_{18}$ sorbent will result in the loss of binding capacity. 
The diluted samples were slowly loaded onto the cartridges taking care not to allow the cartridges to run dry of solvent. Each cartridge was rinsed sequentially with water followed by $10 \%$ acetonitrile in water and then the residual liquid was gently removed from the cartridge using an air filled syringe. The ends of the $\mathrm{C}_{18}$ cartridges were wrapped in Parafilm ${ }^{\circledR}$ (American National Can, Greenwich, CT, USA) and then the entire cartridge was wrapped in aluminium foil and individually labelled, and all cartridges were taped onto and wrapped together in brown wrapping paper. To determine how long fumonisins were stable while bound on the $\mathrm{C}_{18}$ cartridges, fumonisin-loaded $\mathrm{C}_{18}$ cartridges were stored at $22^{\circ} \mathrm{C}$ for $72 \mathrm{~h}$ to simulate 'express' shipping conditions and then for an additional 4 days at $4{ }^{\circ} \mathrm{C}$ to simulate a worst-case scenario for a delay after receipt at the destination and elution of the fumonisins with $2 \mathrm{ml}$ of $70 \%$ acetonitrile in water.

This protocol was chosen to approximate the possible conditions to be encountered during the shipping of loaded $\mathrm{C}_{18}$ cartridges from Guatemala City to Athens, GA, USA. Aliquots of the eluates in $70: 30$ acetonitrile:water (v/v) were diluted with formic acid $(1.73 \%$ in water) so that the final concentration was acetonitrile:water $(30: 70)$ with $1 \%$ formic. Samples were centrifuged at $15000 \mathrm{rcf}$ and $1 \mathrm{ml}$ was transferred to sample vials that contained $10 \mu$ of a $10 \mathrm{ng} \mu \mathrm{l}^{-1}$ Pso internal standard to make a final concentration of $0.1 \mathrm{ng} P s o \mu 1^{-1}$ of sample. For precision data (per cent coefficient of variation, CV), $1 \mathrm{~kg}$ of a sample of clean maize (CM2) and heavily contaminated maize (HCM2) were ground, mixed and $5 \mathrm{~g}$ samples $(n=5)$ were extracted, isolated on $\mathrm{C}_{18}$ cartridges and analysed as described above.

\section{Spiked maize sample preparation}

To determine the extraction efficiency of the method, a total of $1 \mathrm{ml}$ of acetonitrile:water $(1: 1)$ or the working stock solutions of $\mathrm{FB}_{1}, \mathrm{FB}_{2}$, and $\mathrm{FB}_{3}$ in $1: 1$ acetonitrile: water were added to $125 \mathrm{ml}$ flasks containing $5 \mathrm{~g}$ of ground CM1 (six flasks for vehicle and each working solution), thoroughly mixed and air dried at $40^{\circ} \mathrm{C}$ for $16 \mathrm{~h}$. Maize samples were occasionally mixed during drying to ensure uniform distribution of the fumonisins. The target concentration in the ground maize spiked with pure fumonisins was $5 \mu \mathrm{g}$ of each fumonisin $\mathrm{g}^{-1}$ maize. Recoveries of total fumonisins were determined by comparison of the extracts of spiked CM1 to the original working solutions diluted into extracts of CM1 to compensate for matrix effects. The results were corrected for the natural contamination of CM1 with fumonisins.
Preparation of maize extracts for stability and binding studies and for the determination of matrix effects

Five 5-g samples of HCM1 and five $5 \mathrm{~g}$ samples of CM1 were extracted. The extract of CM was used to prepare dilutions of the HCM1 that were $0.25 \mu \mathrm{g} \mathrm{FB}_{1} \mathrm{ml}^{-1}$ (equivalent to extracts of maize with $1.25 \mathrm{mg} \mathrm{kg}^{-1} \quad \mathrm{FB}_{1}$ ) and $1.75 \mu \mathrm{g} \mathrm{FB}_{1} \mathrm{ml}^{-1}$ (equivalent to $8.75 \mathrm{mg} \mathrm{kg}^{-1}$ ). Extracts of HCM1 were also spiked with $\mathrm{FB}_{1}$, taking into account the natural contamination, so as to approximate maize samples with very high levels of fumonisins $\left(300 \mathrm{mg} \mathrm{kg}^{-1}\right)$. These spiked extracts were used to determine if the $\mathrm{C}_{18}$ cartridges were able quantitatively to bind and release fumonisins from maize samples that contained very high levels of fumonisins. The HCM used in these studies also contained $\mathrm{FB}_{2}$ and $\mathrm{FB}_{3}$ and the ratio of $\mathrm{FB}_{1}: \mathrm{FB}_{2}: \mathrm{FB}_{3}$ was approximately $1: 0.3: 0.1$. The pooled extracts of HCM and CM used for determining stability and binding were diluted and analysed by LC-MS/MS to determine the exact final concentrations in the maize extracts.

In order to determine if the $\mathrm{C}_{18}$ eluates had any effects on the ability to quantitate fumonisin, CM2 extracts were subjected to clean-up on the $\mathrm{C}_{18}$ cartridges and then the eluates, processed as described above, were spiked with known amounts of the $\mathrm{FB}_{1}, \mathrm{FB}_{2}, \mathrm{FB}_{3}$ and Pso solutions used for preparing analytical standards (final concentrations $0.01,0.1$ and $1 \mathrm{ng} \mu \mathrm{l}^{-1}$ ). A total of four samples were prepared at each concentration, and the calculated amounts were compared with those of standards prepared in the initial mobile phase $(30 \%$ ' $\mathrm{A}$ ' and $70 \%$ 'B').

\section{Analysis of samples collected in Guatemala, extracted, isolated on $C_{18}$ sorbent and shipped}

In order to test the procedure in a 'real-world' situation, samples were purchased or received as a courtesy from the shop owners of large grain shops in Guatemala City (Department of Guatemala, $n=16$ ). Each sample comprised approximately $1 \mathrm{~kg}$ of dry shelled maize and was placed in individual bags and delivered to the Instituto de Nutricion de Centro America y Panama, where it was stored dry at $-20^{\circ} \mathrm{C}$ until the extraction of fumonisins. Each collected sample was ground using a Romer Mill and then carefully mixed, and a $5 \mathrm{~g}$ sample was extracted and the fumonisins isolated on $\mathrm{C}_{18}$ cartridges as described above. The $\mathrm{C}_{18}$ cartridges were shipped by express mail and were received 2 days after extraction and isolation. Upon receipt, the samples were refrigerated $\left(4^{\circ} \mathrm{C}\right)$ and then on day 3 were eluted and analysed by LC-MS/MS. 


\section{Statistical analysis}

Statistical analysis was performed using Sigma Stat software (Jandel Scientific, San Rafael, CA, USA). One-way analysis of variance (ANOVA) was used followed by tests for post-hoc multiple comparisons where appropriate. All data were expressed as mean \pm standard deviation (SD), and differences among means were considered significant if the probability $(p)$ was $<0.05$.

\section{Results and discussion}

Under the chromatographic conditions used, $\mathrm{FB}_{1}$, $\mathrm{FB}_{2}, \mathrm{FB}_{3}$ and Pso were easily resolved and confirmed by their mass spectra. The approximate retention times for $\mathrm{FB}_{1}, \mathrm{FB}_{2}, \mathrm{FB}_{3}$ and Pso were 8.5, 11.5, 10.5 and $17 \mathrm{~min}$, respectively. Based on the peak areas, the response factors for the three fumonisins were similar (Figure 1). The lower detection limit for $\mathrm{FB}_{1}, \mathrm{FB}_{2}$ and $\mathrm{FB}_{3}$ was less than $0.012 \mathrm{ng}$ injected (equivalent to $0.007 \mu \mathrm{gg}^{-1}$ in maize), and the response was linear up to about $400 \mathrm{ng}$ injected (equivalent to $233 \mu \mathrm{g} \mathrm{g}^{-1}$ in maize), after which the response was no longer linear (Figure 1). When amounts greater than $12 \mathrm{ng}$ were injected, fumonisins were detected in subsequent solvent blanks (Figure 1). This has been reported previously and is attributed to the tendency of fumonisins to be reversibly adsorbed by the column-packing material (Plattner et al. 1996). The fact that the Pso response was constant over the entire range of injected fumonisins suggests that the decreased response seen at the highest levels of injected fumonisins was not a result of overloading the capacity of the HPLC column, but most likely a consequence of the concentration of ions entering the ion trap being so great that the ion trap overfilled, leading to space charging, with the net result being a drop off in linearity. Nonetheless, the LC-MS/MS method using the $\mathrm{LCQ}^{\mathrm{TM}}$ Duo was linear over four orders of range, which is more than sufficient to allow the accurate quantification of fumonisins in naturally contaminated maize.

Pso is a natural component of plant tissues and low levels were detected in the $\mathrm{C}_{18}$-cartridge eluates of both CM and HCM (Figure 2). The HCM contained significantly more Pso than the CM, which would not be surprising in growing plants, but which is unexpected in ungerminated maize kernels. Fumonisins are inhibitors of ceramide synthase in maize seedling and cause the accumulation in roots of both Pso and sphinganine, which is the precursor of Pso (Riley et al. 1996). Regardless, the amount of Pso added to $\mathrm{C}_{18}$-cartridge eluates was nine to 34 times greater than the contribution

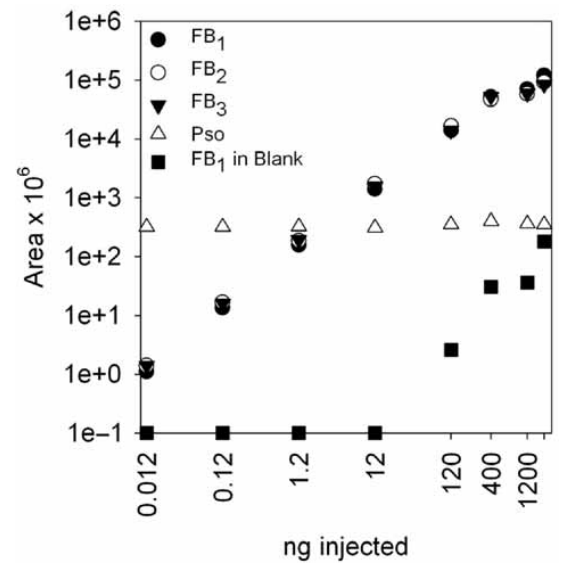

Figure 1. Quantitation of fumonisins $\mathrm{B}_{1}\left(\mathrm{FB}_{1}\right), \mathrm{FB}_{2}$ and $\mathrm{FB}_{3}$ by liquid chromatography coupled with tandem mass spectrometry detection (LC-MS/MS) and carry over of $\mathrm{FB}_{1}$ in the solvent blanks injected following each sample concentration (a 20- $\mu$ l injection ranging from 0.0006 to $100 \mathrm{ng} \mathrm{l}^{-1}$ ). Also shown is the response of the phytosphingosine (Pso) at $0.1 \mathrm{ng} \mu \mathrm{l}^{-1}$ injected with each sample. The standards were prepared by adding known amounts of fumonisin stock solutions to $1 \mathrm{ml}$ of the initial mobile phase $(30 \% \mathrm{~A}: 70 \% \mathrm{~B})$.

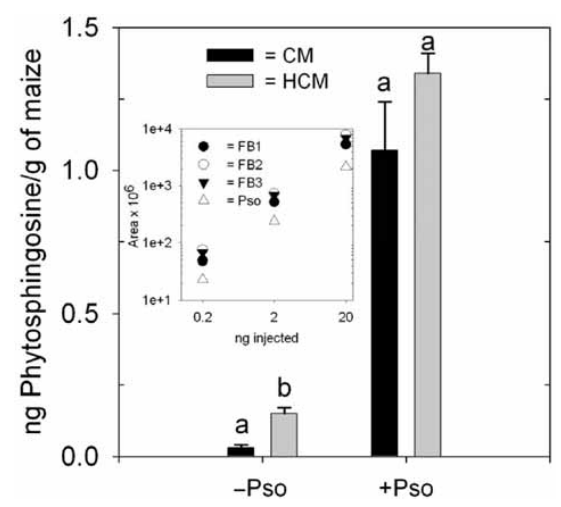

Figure 2. Phytosphingosine levels in clean maize (CM) and heavily contaminated maize (HCM) extracts after clean-up on $\mathrm{C}_{18}$ cartridges and prepared for injection without added phytosphingosine (-Pso) and with added phytosphingosine (+Pso), as described in the Materials and methods. Values are the mean $\pm \mathrm{SD}$ ( $n=3$ extracts) and means within treatments with differing letter superscripts were significantly different $(p<0.05)$. The inset shows the response (peak areas) for the injection of standards containing various amounts of fumonisins $\left(\mathrm{FB}_{1}, \mathrm{FB}_{2}\right.$, $\mathrm{FB}_{3}$ ) and phytosphingosine (Pso).

from endogenous Pso when injected. Under the conditions optimized for $\mathrm{FB}_{1}$, the Pso response is less than that for the fumonisins, but it is still linear over a wide concentration range (Figure 2, inset). The addition of the Pso has proven useful when monitoring instrument performance. For example, partial plugging of the heated capillary, forward movement of the fused silica sample tube in the ESI needle, or build up of residual materials on the tube lens and skimmer. 
The eluate from the $\mathrm{C}_{18}$ cartridges did not interfere with the LC/MS detection of fumonisins (Figure 3). There was no significant difference between the amounts of $\mathrm{FB}_{1}$ quantified in the sample solvent (standards) and in the $\mathrm{C}_{18}$-cartridge eluates of CM spiked with the same amounts of fumonisins (Figure 3). In addition, while instrument performance was often adversely affected (plugging of the heated capillary) after multiple injections of the CM extracts that were not cleaned-up on the $\mathrm{C}_{18}$ cartridges, the $\mathrm{C}_{18}$-cartridge eluates of the $\mathrm{CM}$ had

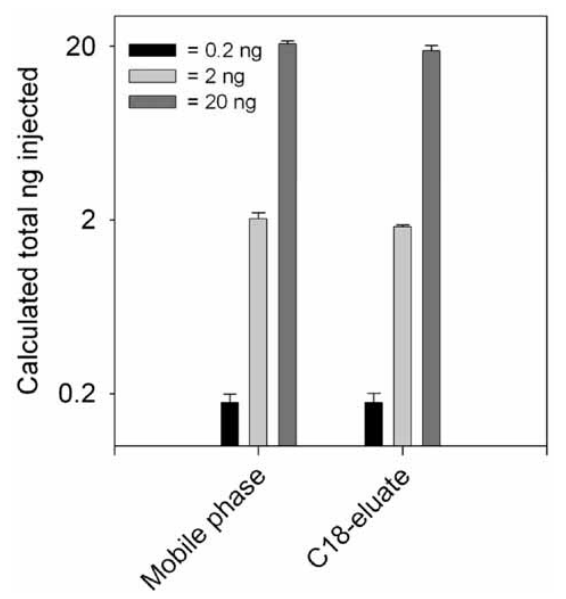

Figure 3. Calculated total injected nanograms of $\mathrm{FB}_{1}$ in samples $(n=4)$ dissolved in the initial mobile phase or in $\mathrm{C}_{18}$-cartridge eluates so as to contain $0.2,2.0$ or $20 \mathrm{ng}$ total $\mathrm{FB}_{1}$ in a $20-\mu \mathrm{l}$ injection. Similar results were obtained for $\mathrm{FB}_{2}, \mathrm{FB}_{3}$ and Pso (data not shown). Values are means $\pm S D$. no appreciable effect on instrument performance after 16 sequential injections (Table I). More recently, up to 40 samples have been injected sequentially with no apparent adverse effect on instrument performance. The precision analysis for $\mathrm{FB}_{1}$ using $\mathrm{C}_{18}$-cartridge eluates of extracts $(5 \mathrm{~g}$ samples; $n=5$ ) of maize containing an average of $0.04,1.23,9.1$ and $53.6 \mu \mathrm{gg}^{-1}$ showed that the coefficient of variation (per cent of SD) was 17, 5, 3 and $9 \%$, respectively. The results were similar for $\mathrm{FB}_{2}$ and $\mathrm{FB}_{3}$ (data not shown).

The recoveries of $\mathrm{FB}_{1}, \mathrm{FB}_{3}$ and $\mathrm{FB}_{2}$ from maize samples $(n=6)$ spiked with fumonisins at a level equivalent to $5 \mu \mathrm{g}$ of each fumonisin $\mathrm{g}^{-1}$ maize were $57 \% \pm 3.7 \%, 63.5 \% \pm 4.5 \%$ and $68.9 \% \pm 5.3 \%$ for $\mathrm{FB}_{1}, \mathrm{FB}_{3}$ and $\mathrm{FB}_{2}$, respectively. The recoveries from the spiked maize samples were quantified using standards prepared from stock solutions dissolved in unspiked maize extracts and corrected for their natural fumonisin content. The mean recovery of $\mathrm{FB}_{2}$ was significantly $(p \leq 0.05)$ greater than that of $\mathrm{FB}_{1}$ and $\mathrm{FB}_{3}$ This may be attributed to the fact that $\mathrm{FB}_{1}$ is more polar than $\mathrm{FB}_{2}$, which has one less hydroxyl group, and presumably $\mathrm{FB}_{2}$ is less polar than $\mathrm{FB}_{3}$, as evidenced by the fact that the elution of $\mathrm{FB}_{3}$ and $\mathrm{FB}_{2}$ occur at approximately 48 and $54 \%$ of acetonitrile, respectively, in the mobile phase based on their retention times. These differences in polarity could result in slight differences in the extractability of the fumonisins into the acetonitrile: water extraction solvent. However, it is also possible that the heating of the spiked maize samples to $40^{\circ} \mathrm{C}$ for $16 \mathrm{~h}$ resulted in $\mathrm{FB}_{1}$ being more

Table I. Results of the analysis of 16 maize samples collected from markets in Guatemala City, then extracted and isolated on $\mathrm{C}_{18}$ cartridges and express-mailed to the USA for elution and analysis by liquid chromatography/mass spectrometry/mass spectrometry (LC-MS/MS). The final concentration for each fumonisin is corrected for the extraction efficiencies.

\begin{tabular}{lccccc}
\hline Sample number & $\mathrm{FB}_{1}\left(\mu \mathrm{gg}^{-1}\right)$ & $\mathrm{FB}_{2}\left(\mu \mathrm{gg}^{-1}\right)$ & $\mathrm{FB}_{3}\left(\mu \mathrm{gg}^{-1}\right)$ & $\left(\mathrm{FB}_{1}+\mathrm{FB}_{2}+\mathrm{FB}_{3}\right)$ & $\mathrm{Pso}^{\mathrm{a}}\left(\mathrm{ng} \mathrm{ml}^{-1}\right)$ \\
\hline 1 & 13.49 & 3.51 & 1.35 & 1.36 & 0.090 \\
2 & 1.76 & 0.33 & 0.17 & 1.28 & 0.082 \\
3 & 2.53 & 0.42 & 0.17 & 1.23 & 0.088 \\
4 & 3.16 & 0.76 & 0.28 & 1.33 & 0.099 \\
5 & 0.81 & 0.14 & 0.06 & 1.25 & 0.121 \\
6 & 6.65 & 1.17 & 0.74 & 1.31 & 0.110 \\
7 & 7.02 & 1.34 & 0.83 & 1.26 & 0.074 \\
8 & 1.42 & 0.27 & 0.10 & 1.19 & 0.074 \\
9 & 1.04 & 0.14 & 0.06 & 1.33 & 0.094 \\
10 & 5.81 & 1.49 & 0.43 & 1.20 & 0.121 \\
11 & 0.48 & 0.07 & 0.02 & 1.31 & 0.110 \\
12 & 0.99 & 0.20 & 0.11 & 1.25 & 0.110 \\
13 & 19.34 & 7.26 & 1.83 & 1.25 & 0.114 \\
14 & 0.12 & 0.03 & 0.02 & 1.26 & 0.122 \\
15 & 0.60 & 0.11 & 0.04 & 1.29 & 0.104 \\
16 & 0.56 & 0.12 & 0.03 & $(0.07)$ & 0.102 \\
Mean & 4.11 & 1.08 & 0.39 & $(0.54)$ & $(0.016)$ \\
SD & $(5.40)$ & $(1.87)$ & $0.1 \mathrm{n}$ &
\end{tabular}

$\overline{{ }^{a}}$ Concentration of phytosphingosine spiked into each vial was $0.1 \mathrm{ng} \mu 1^{-1}$ and was used as an indicator of instrument performance. 


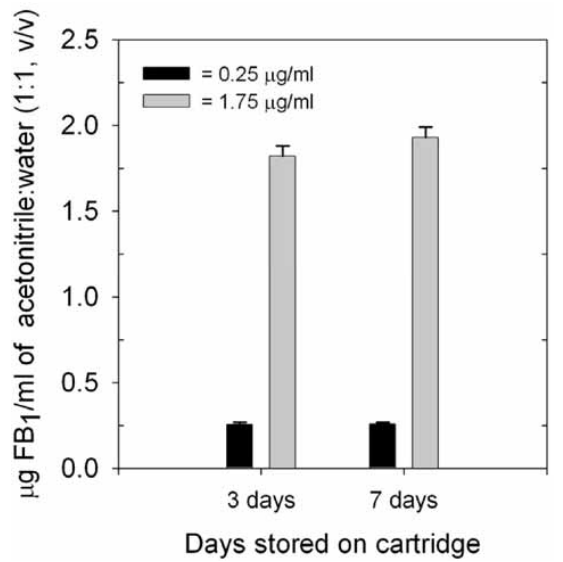

Figure 4. Stability of $\mathrm{FB}_{1}$ extracted from maize and then loaded onto $\mathrm{C}_{18}$ cartridges and stored at $22^{\circ} \mathrm{C}$ for 3 days ( $n=5 /$ concentration) and then an additional 4 days at $4^{\circ} \mathrm{C}$ ( $n=5 /$ concentration) for a total of 7 days. The concentrations of fumonisin in the solutions loaded on the cartridges were 0.25 and $1.75 \mu \mathrm{g} \mathrm{ml}^{-1}$, which were equivalent to maize contaminated at 1.25 and $8.75 \mu \mathrm{g} \mathrm{FB}_{1} \mathrm{~g}^{-1}$ maize, respectively. The amount of $\mathrm{FB}_{1}$ in the eluate following the solid-phase clean-up was compared with the $\mathrm{FB}_{1}$ content of the original solutions used for loading the columns. The eluates containing the high concentration of $\mathrm{FB}_{1}$ were diluted with the initial mobile phase before analysis. Values are the mean $\pm \mathrm{SD}$.

tightly bound to compounds in the maize matrix compared with the binding of $\mathrm{FB}_{2}$ and $\mathrm{FB}_{3}$. The average recoveries in this study were less than earlier studies using methanol:water (3:1, v/v), where mean recoveries ranged from 76 to $87 \%$ (Sydenham et al. 1996), and acetonitrile:water $(1: 1, \mathrm{v} / \mathrm{v})$, where mean recoveries ranged from 81 to $100 \%$ for $\mathrm{FB}_{1}, \mathrm{FB}_{2}$ and $\mathrm{FB}_{3}$ (Rice et al. 1995). Nonetheless, using acetonitrile:water extraction in the present study, the coefficients of variation (expressed as SD as a per cent of the mean) were less than $10 \%$, which indicated that the method was reproducible and the compatibility of the acetonitrile with the subsequent isolation on $\mathrm{C}_{18}$ cartridges and the desire to avoid methylation of the fumonisins during storage and shipping led the authors to prefer acetonitrile as an extraction solvent.

Once loaded onto $\mathrm{C}_{18}$ cartridges, fumonisins from maize extracts are stable for at least 3 days at $22^{\circ} \mathrm{C}$ and an additional 4 days at $4^{\circ} \mathrm{C}$ at fumonisin concentrations, which were equivalent to 1.25 and $8.75 \mathrm{mg} \mathrm{kg}^{-1} \mathrm{FB}_{1}$ in maize, respectively (Figure 4). The mean recoveries of $\mathrm{FB}_{1}, \mathrm{FB}_{2}$ and $\mathrm{FB}_{3}$ from the $\mathrm{C}_{18}$ cartridges ranged from $102 \% \pm 5 \%$ to $110 \% \pm 11 \%$ of what was loaded onto the cartridges (data for $\mathrm{FB}_{2}$ and $\mathrm{FB}_{3}$ not shown). The recoveries were very close to the predicted recoveries based on the analysis of the maize extracts. In the early stages of developing the protocol for loading the $\mathrm{C}_{18}$ cartridges, it was discovered that it is critical that columns are not allowed to become dry during the equilibration with solvents before the maize extracts are loaded. If the column is allowed to become dry, then the binding capacity is reduced and recoveries will not be quantitative. According to the manufacture (Waters, Milford MA, USA), the reduced recoveries are due to the hydrophobic collapse of the bonded phase of the $\mathrm{C}_{18}$ cartridge. When the $\mathrm{C}_{18}$ cartridges were loaded with maize extracts containing $\mathrm{FB}_{1}$ at a concentration equivalent to maize contaminated at $300 \mathrm{mg} \mathrm{kg}^{-1}, 98 \% \pm 3.2 \% \quad(n=3)$ of the $\mathrm{FB}_{1}$ was recovered in the eluate, which indicates that extracts of naturally contaminated maize samples would seldom, if ever, be able to overload the fumonisin-holding capacity of the $\mathrm{C}_{18}$ cartridge.

All 16 samples collected from the markets in Guatemala City contained detectable levels of $\mathrm{FB}_{1}$, $\mathrm{FB}_{2}$ and $\mathrm{FB}_{3}$ (Table I). The total fumonisins $\left(\mathrm{FB}_{1}+\mathrm{FB}_{2}+\mathrm{FB}_{3}\right)$ in the samples ranged from 0.17 to $28.4 \mathrm{mg} \mathrm{kg}^{-1}$. The 16 samples were loaded in the autosampler and injected in the sequence shown in Table I. The levels of Pso showed no trend indicative of decreasing instrument performance over the course of the sequence. All the samples obtained at the markets in Guatemala City were intended to be sold for human consumption and were harvested between November 2004 and January 2005 from various locations. The results show that fumonisins are present in maize consumed in Guatemala.

In conclusion, a simple, safe and legal method for shipping fumonisins from extracts of maize bound to $\mathrm{C}_{18}$ cartridges for fumonisin analysis has been developed and is compatible with analysis by iontrap LC/MS. While strong anion exchange columns are also frequently used to bind fumonisins, and may also serve as a way to ship samples, the advantage of the $\mathrm{C}_{18}$ cartridge is that it can also be used to isolate hydrolysed fumonisins (Plattner 1999), which are frequently found in maize products consumed in Guatemala (Meredith et al. 1999; Palencia et al. 2003). The results indicate that fumonisins in acetonitrile: water extracts of maize can be isolated on $\mathrm{C}_{18}$ cartridges, held for at least 3 days at $22^{\circ} \mathrm{C}$ and then an additional 4 days at $4^{\circ} \mathrm{C}$ before elution and analysis with no losses. This method will facilitate the importation and analysis of a large number of maize samples from distant foreign locations and will avoid complications arising from international safety concerns and obviates the requirement for US Animal Plant Health Inspection Service permits. This approach may also be useful for shipping samples into other countries where the importation of plant materials is restricted by law. In addition, the eluates from the $\mathrm{C}_{18}$ 
cartridges are compatible with analysis by ESI ion-trap LC/MS.

\section{Acknowledgement}

The authors thank Mrs A. Jency Showker for expert technical assistance and good humour. The work was supported by the US Department of Agriculture (USDA) FAS Grant No. X01-4510-62-751071-4, by the International Life Science Institute of North America Technical Committee on Food Toxicology and Safety Assessment, and by the Pan American Health Organization.

\section{References}

Bolger M, Coker RD, Dinovi M, Gaylor D, Gelderblom WCA, Paster N, Riley RT, Shephard G, Speijers JA. 2001. Fumonisins. In: Safety evaluation of certain mycotoxins in food. Food and Agriculture Organization of the United Nations Paper No. 74. World Health Organization Food Additives Series No. 47. Rome: FAO/WHO. pp 103-279.

International Agency for Research on Cancer (IARC). 2002. Fumonisin $\mathrm{B}_{1}$. Monographs on the Evaluation of Carcinogenic Risks to Humans: Some Traditional Medicines, Some Mycotoxins, Naphthalene and Styrene No. 82. Lyon: IARC. pp 301-366.

Joseph JL. 1996. Detection and characterization of fumonisin mycotoxins by liquid chromatography/electrospray ionization using ion trap and triple quadrupole mass spectrometry. Rapid Communications in Mass Spectrometry 10:1333-1344.

Marasas WFO, Riley RT, Hendricks KA, Stevens VL, Sadler TW, Gelineau-van Waes J, Missmer SA, Cabrera Valverde J, Torres OL, Gelderblom W, et al. 2004. Fumonisins disrupt sphingolipid metabolism, folate transport and development of neural crest cells in embryo culture and in vivo: A risk factor for human neural tube defects among populations consuming fumonisin-contaminated maize? Journal of Nutrition 134:711-716.
Meredith FI, Torres OR, Riley RT, Merrill AH, Jr. 1999. Fumonisin B1 and hydrolyzed fumonisin B1 levels in nixtamalized maize (Zea mays 1.) and tortillas from two different geographical locations in Guatemala. Journal of Food Protection 62:1218-1222.

Musser SM. 1996. Quantification and identification of fumonisins by liquid chromatography/mass spectrometry. Advances in Experimental Medicine and Biology 392:65-74.

Palencia E, Torres O, Hagler W, Meredith FI, Williams LD, Riley RT. 2003. Total fumonisins are reduced in tortillas using the traditional nixtamalization method of Mayan communities. Journal of Nutrition 133:3200-3203.

Plattner RD. 1999. HPLC/MS analysis of Fusarium mycotoxins, fumonisins and deoxynivalenol. Natural Toxins 7:365-370.

Plattner RD, Branham BE. 1994. Labeled fumonisin: Production and use of fumonisin B1 containing stable isotopes. Journal of the Association of Official Analytical Chemists International 77:525-532.

Plattner RD, Weisleder D, Poling SM. 1996. Analytical determination of fumonisins and other metabolites produced by Fusarium moniliforme and related species on corn. Advances in Experimental Medicine and Biology 392:57-64.

Rheeder JP, Marasas WFO, Vismer HF. 2002. Production of fumonisin analogs by Fusarium species. Applied and Environmental Microbiology 68:2101-2105.

Rice LG, Ross PF, Dejong J, Plattner RD, Coats JR. 1995. Evaluation of a liquid chromatographic method for the determination of fumonisins in corn, poultry feed, and Fusarium culture material. Journal of the Association of Official Analytical Chemists International 78:1002-1009.

Riley RT, Wang E, Schroeder JJ, Smith ER, Plattner RD, Abbas H, Yoo H-S, Merrill AH, Jr. 1996. Evidence for disruption of sphingolipid metabolism as a contributing factor in the toxicity and carcinogenicity of fumonisins. Natural Toxins 4:3-15.

Shephard GS. 1998. Chromatographic determination of the fumonisin mycotoxins. Journal of Chromatography A 815:31-39.

Sydenham EW, Shephard GS, Thiel P, Stockenstrom GS, Snijman PW, Van Schalkwyk DJ. 1996. Liquid chromatographic determination of fumonisins B1, B2 and B3 in corn: AOAC-IUPAC collaborative study. Journal of the Association of Official Analytical Chemists International 79:688-696. 